\title{
PEMODELAN ARSITEKTUR ENTERPRISE SISTEM INFORMASI CUSTOMER RELATIONSHIP MANAGEMENT MENGGUNAKAN ENTERPRISE UNIFIED PROCESS
}

\author{
Ahmad Mubarok ${ }^{1}$, Djaja Sukma Tjahjadi ${ }^{2}$ \\ 19ahmadmubarok@stmik-kharisma.ac.id, 2djaja@likmi.ac.id \\ ${ }^{1}$ STMIK Kharisma Karawang, ${ }^{2}$ STMIK LIKMI Bandung
}

\begin{abstract}
Abstrak
Teknologi informasi memiliki peranan penting dalam perusahaan atau instansi untuk menjalankan proses bisnisnya. Teknologi informasi dapat membantu mengoptimalkan kelangsungan bisnis perusahaan seperti pada proses pelayanan pelanggan. Perusahaan membutuhkan sebuah sistem informasi untuk mengelola hubungan antara pelanggan dengan perusahaan yaitu dengan konsep Customer Relationship Management (CRM). Tahap awal dalam pengembangan sistem informasi adalah merancang sebuah arsitektur, meliputi arsitektur teknologi, arsitektur data dan arsitektur proses bisnis. Unified Process (UP) adalah suatu kerangka kerja dari proses perangkat lunak yang instantiated, baik Rational Unified Process (RUP) maupun Enterprise Unified Process (EUP). Arsitektur sistem informasi CRM yang dibangun menggunakan metode Enterprise Unfief Process merupakan sebuah rancangan aristektur enterprise yang dapat dijadikan acuan untuk membangun sebuah sistem berbasis CRM yang dapat meningkatkan core value dalam pelayanan terhadap customer. Hasil dari penelitian ini adalah rekomendasi model arsitektur sistem informasi beserta metode yang digunakan untuk mencapai sasaran strategis organisasi terutama dalam hal pelayanan pelanggan.
\end{abstract}

Kata kunci: Arsitektur, Customer Relationship Management, Enterprise Unified Process, Sistem informasi.

Abstract

The information technology has an important role in a company or agency to run its business process. It can help to optimize the business continuity as in the customer service process. In this case, the company needs an information system to manage the relationship between the customer and company applied into the concept of Customer Relationship Management (CRM). The initial stage in the development of information systems is to design architecture including: technology architecture, data architecture, and business process architecture. The Unified Process (UP) is a framework of the instantiated software process, both the Rational Unified Process (RUP) and Enterprise Unified Process (EUP). The information system architecture of CRM uses the Enterprise UP method. It is an enterprise architecture design that can be used as a reference to build a CRM-based system that can increase core value in service to customers. The results of this study are recommendations for information systems architecture models and methods used to achieve the strategic goals of the organization, especially in terms of customer service.

Keywords: Architecture, Customer Relationship Management, Enterprise Unified Process, Information System

\section{Pendahuluan}

Tata kelola teknologi informasi yang baik menjadi prioritas utama dalam penyelenggaraan pelayanan publik [1]. Good Governance diikuti dengan perubahan pola pikir yang dilakukan oleh perusahaan yang berfokus pada benefit kini telah mengalami perubahan yakni ke arah faktor potensial lainnya seperti customer focus untuk meningkatkan mutu pelayanan terhadap pelanggan [2]. Banyak kasus dalam pemanfaatan Sistem Informasi mengalami kegagalan dalam mencapai sasaran (objective) organisasi karena pemanfaatan ini berjalan tidak sesuai dengan tujuan serta kebutuhan Institusi (organisasi). Sistem informasi merupakan kombinasi antara prosedur kerja, informasi, orang dan teknologi informasi yang diorganisasikan untuk mencapai tujuan dalam sebuah organisasi [3].

Dalam hal pemodelan arsitektur, terdapat beberapa metodologi yang dapat digunakan dalam sistem informasi, salah satu diantaranyanya adalah Enterprise Unified Process (EUP). EUP adalah sebuah siklus pengembangan teknologi informasi perluasan dari Rational Unified Process (RUP) [4]. RUP merupakan satu set best practise software engineering method yang mempunya ciri utama yaitu use case driver [5]. Sementara itu, EUP tidak hanya menangani siklus pengembangan perangkat 
ILKOM Jurnal Ilmiah Volume 11 Nomor 3 Desember 2019 Terakreditasi peringkat 3 SK. No. 28/E/KPT/2019

lunak tetapi mencakup seluruh siklus hidup Teknologi Informasi dan menambahkan disiplin enterprise management dengan melakukan cross-system terhadap kebutuhan suatu arsitektur enterprise.

Pentingnya informasi digital seperti pada hubungan antara perusahaan dan pelanggan tidak terlepas dari tuntutan dalam memberikan pelayanan yang maksimal. Salah faktor penting dalam bersaing dengan kompetitor yakni dengan meningkatkan layanan terhadap pelanggan dan menerapkan konsep manajemen hubungan pelanggan atau Customer Relationship Management (CRM) [6]. CRM merupakan suatu strategi perusahaan yang digunakan untuk memanjakan pelanggan agar tidak berpaling kepada pesaing [7]. Dengan penerapan Sistem Informasi CRM diharapkan dapat meningkat kualitas layanan terhadap customer. Penerapan CRM bukan hanya untuk mempertahan pelanggan yang ada, namun juga untuk menarik para calon pelanggan baru sehingga dapat mulai berinteraksi dan menajalin kerjasama dengan perusahaan [8].

Dalam penelitian sebelumnya seperti pada jurnal Implementasi CRM Pada Penerimaan Siswa Baru yang dilakukan oleh Abdurrahman dkk [9], yang bertempat di Pondok Pesantren Darussalam Kabupaten Garut berfokus pada peningkatan kualitas pelayanan terhadap peserta didik. Penelitian lainnya yaitu Pengaruh Customer Relationship Management Dan Kepercayaan Terhadap Kepuasan Serta Dampaknya Terhadap Loyalitas Konsumen PT. Bank Bca Tbk. Di Manado yang dilakukan oleh Victor dkk. [8], berfokus pada peningkatan kepercayaan dan pelayanan terhadap nasabah. Dan penelitian yang dilakukan oleh Dyantina dkk [2], yang berjudul Penerapan Customer Relationship Management Berbasis Web (Studi Kasus Pada Sistem Informasi Pemasaran di Toko YEN-YEN) yakni meningkatkan pelayanan pelanggan dan strategi marketing. Beberapa penelitian sebelumnya belum ditemukan pengembangan sistem informasi berbasis CRM yang dilakukan pada industrial estate dan menggunakan metode arsitektur enterprise yaitu EUP.

PT.XYZ merupakan perusahaan yang bergerak dibidang industrial estate, PT.XYZ dalam melayani customer masih menggunakan sistem konvensional yaitu dengan melalui surat pemberitahuan atau telepon. Namun, layanan dengan metode konvensional tersebut dianggap kurang optimal dan efisien. Salah satu penyebabnya adalah belum adanya sistem yang dibuat dan dikelola dengan baik oleh perusahaan sehingga pelayanan dan tatakelola tidak tampak seperti piramida yang menunjukkan gambaran hubungan perusahaan dan pelanggan. Atas hal tersebut maka tujuan penelitian ini adalah membangun arsitektur enterprise yang bisa dijadikan acuan pengembangan $\mathrm{TI} / \mathrm{SI}$ serta membuat rekomendasi sistem yang strategis berbasis CRM untuk mendukung proses bisnis organisasi berikut dengan metode yang digunakan dalam membangun sistem informasi.

\section{Metode}

Gambar 1 menunjukkan kerangka penelitian yang meliputi disiplin-disiplin dalam EUP yang diakhiri dengan kesimpulan dan usulan terhadap implementasinya [9]. Setiap tahap menghasilkan output sesuai dengan kajian penelitian.

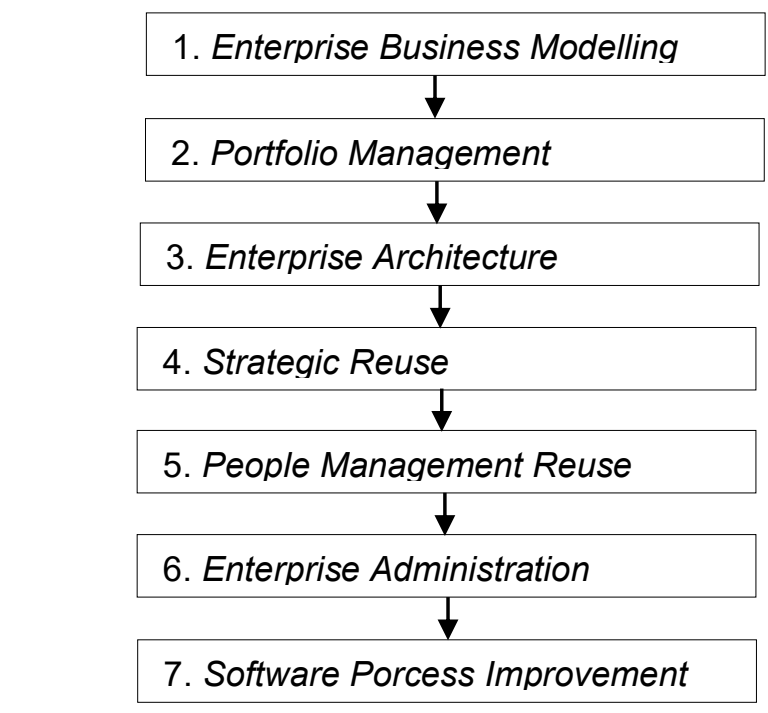

Gambar 1. Metodologi Perencanaan Arsitektur Enterprise 


\section{Arsitektur}

Arsitektur adalah hubungan kerja terstruktur dari sebuah sistem yang terdiri dari hardware, software dan network [10]. Arsitektur juga dikenal sebagai dasar sistem organisasi yang menghubungkan komponen-komponen pada lingkungan sistem dan memiliki aturan perancangan dan evaluasi. Arsitektur (architecture) dalam pembahasan tentang sistem informasi bersekala enterprise didefinisikan sebagai The structure of components, the interrelationships, and the principles and guidelines their design and evolution over time [11]. Pengertian tersebut memiliki makna bahwa arsitektur pada dasarnya adalah berupa gambaran sebuah struktur perusahaan/lembaga/institusi yang terdiri dari berbagai macam komponen pendukung dan relasi antar komponen tersebut.

\section{Enterprise Architecture}

Pada umumnya arsitektur enterprise didefinisikan sebagai model, dokumentasi, dan item-item yang dapat digunakan kembali seperti komponen, kerangka kerja (framework), obyek dan sebagainya yang mencerminkan sebuah arsitektur secara utuh [9]. EA Community (www.eacommunity.com) mendefinisikan sebagai kerangka kerja atau blueprint untuk bagaimana organisasi mencapai tujuan bisnis saat ini dan masa depan dengan cara menguji kunci sukses bisnis, informasi, aplikasi dan strategi teknologi dan dampaknya terhadap fungsi bisnis. Masing-masing strategi ini adalah disiplin arsitektur yang terpisah dan EA adalah perekat yang mengintegrasikan masing-masing disiplin dalam kerangka yang kohesif seperti ditunjukkan pada Gambar 2.

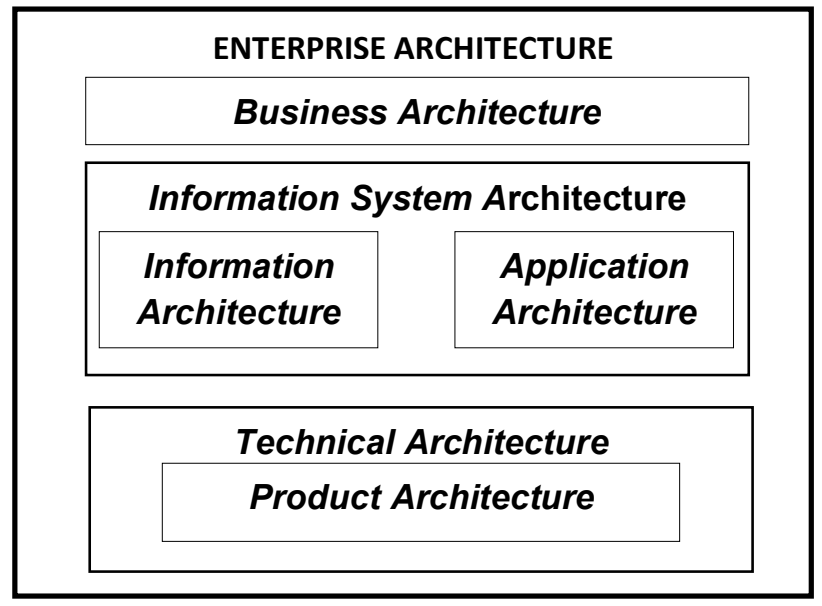

Gambar 2. Hubungan Antar Arsitektur dalam EA [12]

\section{Customer Relationship Management}

Customer Relationship Management (CRM) adalah strategi inti dalam bisnis yang mengintegrasikan proses-proses dan fungsi-fungsi internal dengan semua jaringan eksternal untuk menciptakan serta mewujudkan nilai bagi para konsumen sasaran secara profitable [13]. CRM pada intinya merupakan kolaborasi dengan setiap konsumen yang mampu menciptakan keadaan yang tidak merugikan salah satu pihak (win-win situation) [13]. Aspek utama yang disimpulkan bahwa CRM adalah:

1. Bagaimana perusahaan menemukan customer.

2. Bagaimana perusahaan dapat mengenal customer.

3. Bagaimana perusahaan dapat tetap berhubungan dengan customer.

4. Bagaimana perusahaan memastikan anda mendapatkan apa yang customer mau dari seluruh aspek yang perusahaan berikan.

5. Bagaimana perusahaan memeriksa customer mendapatkan apa yang kami janjikan.

\section{Analisis Value Chain}

Fungsi dari value added chain yaitu untuk mendeskripsikan cara melihat bisnis sebagai rantai aktifitas yang mengubah input menjadi output sehingga memiliki nilai bagi pelanggan [14]. Prinsip dari value chain adalah bagaimana memetakan seluruh proses kerja atau aktivitas dalam institusi tersebut ke dalam dua bagian yaitu, aktivitas utama dan aktivitas pendukung [15]. 
ILKOM Jurnal IImiah Volume 11 Nomor 3 Desember 2019

Terakreditasi peringkat 3 SK. No. 28/E/KPT/2019

Pada Gambar 3, Value chain dibagi dalam dua kategori, yaitu Primary activities (line functions) yang merupakan aktifitas utama dari organisasi kemudian yang kedua adalah Secondary Activities (staff atau fungsi overhead) yang merupakan aktifitas pendukung untuk membantu aktifitas utama.

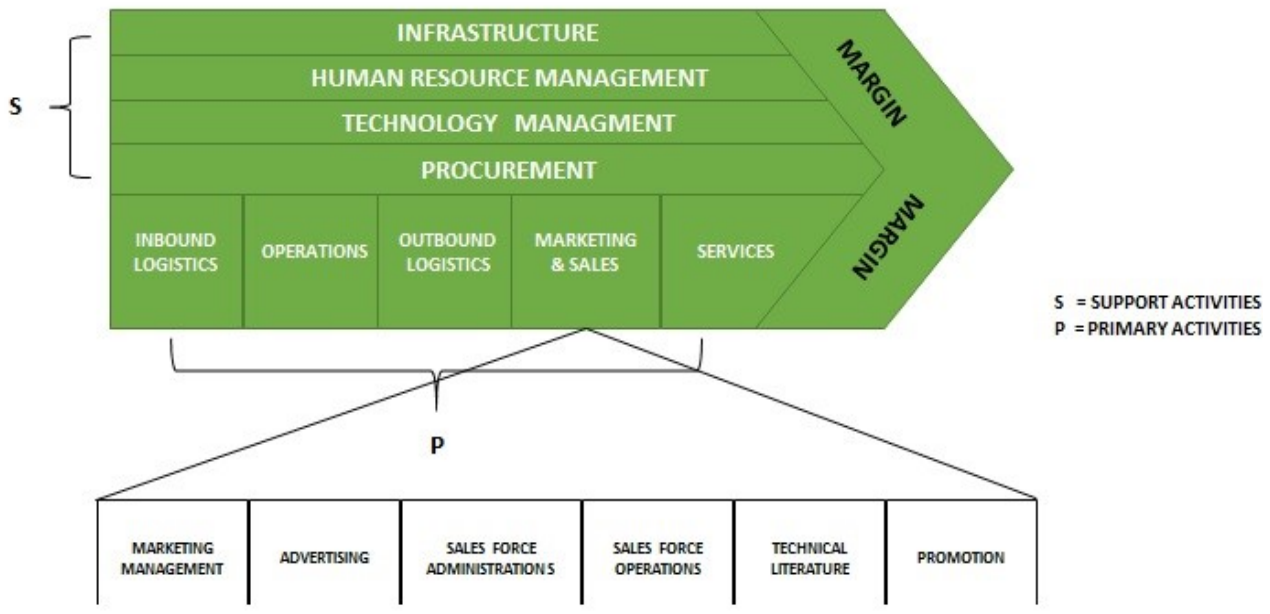

Gambar 3. Value Added Chain [14]

\section{Hasil dan Pembahasan}

\section{Enterprise Business Modelling}

Penelitian ini dilakukan pada perusahaan yang bergerak di bidang properti yaitu sebagai pengelola kawasan industri dan memiliki aktivitas utama dalam memberikan pelayanan terhadap customer. Pada aktivitas utama akan memerlukan dukungan dari aktivitas lainnya seperti bagian Procurement dan bagian Information Technology atau Technology management. Identifikasi aktivitas utama dan pendukung diperusahaan dapat diuraikan dengan menggunakan rantai nilai (value chain) dari Michael E. Porter yang tampak seperti Gambar 4.

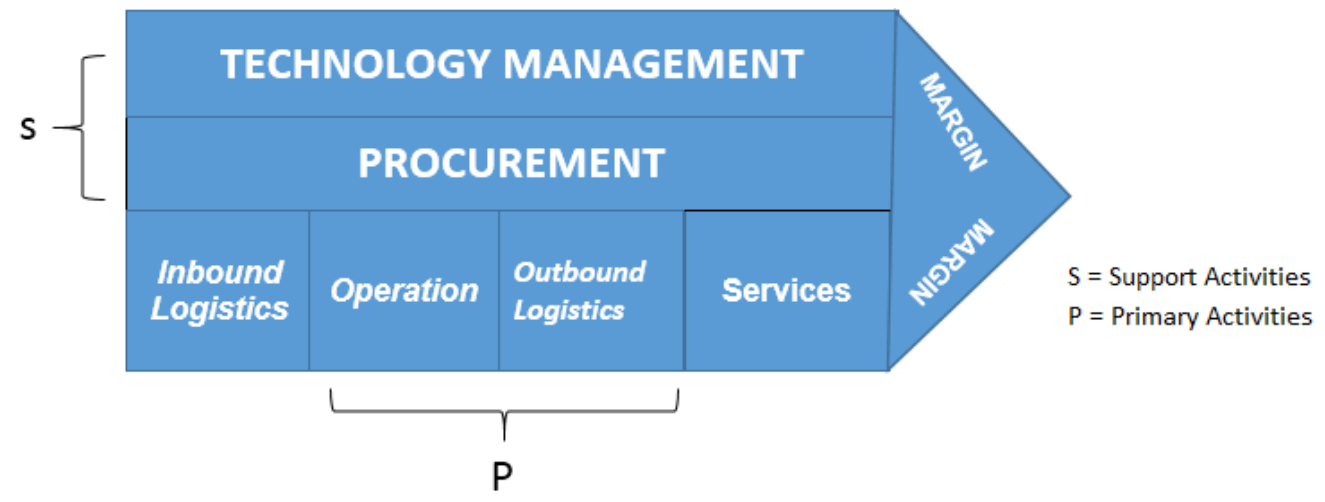

Gambar 4. Value Chain Analysis pelayanan pelanggan

Aktivitas utama yang harus dilakukan untuk mencapai tujuan bisnis pada perusahaan adalah:

1. Menerima pelaporan atau komplain dari tenant terkait dengan layanan publik, sarana dan prasana yang ada di kawasan industri.

2. Melakukan penanganan kasus berdasarkan pelaporan yang dilayangkan oleh tenant

3. Memberikan laporan kepada tenant terkait hasil penyelesaian kasus yang telah selesai ditangani.

4. Memberikan pelyanan dan menyediakan fasilitas publik kepada tenant.

Aktivitas pendukung harus dilakukan untuk mencapai tujuan bisnis yang meliputi:

1. Teknologi management yang menyediakan sistem informasi yang menghubungkan antara tenant dengan perusahaan.

2. Melakukan pengadaan infrastruktur pelayanan publik. 
ILKOM Jurnal Ilmiah Volume 11 Nomor 3 Desember 2019

Terakreditasi peringkat 3 SK. No. 28/E/KPT/2019

Untuk menggambarkan bisnis proses di perusahaan maka digunakan use case bisnis seperti oada Gambar 5 yang merupakan impelementasi tahap pertama dari disiplin enterprise management EUP yaitu Enterprise Business Modeling.

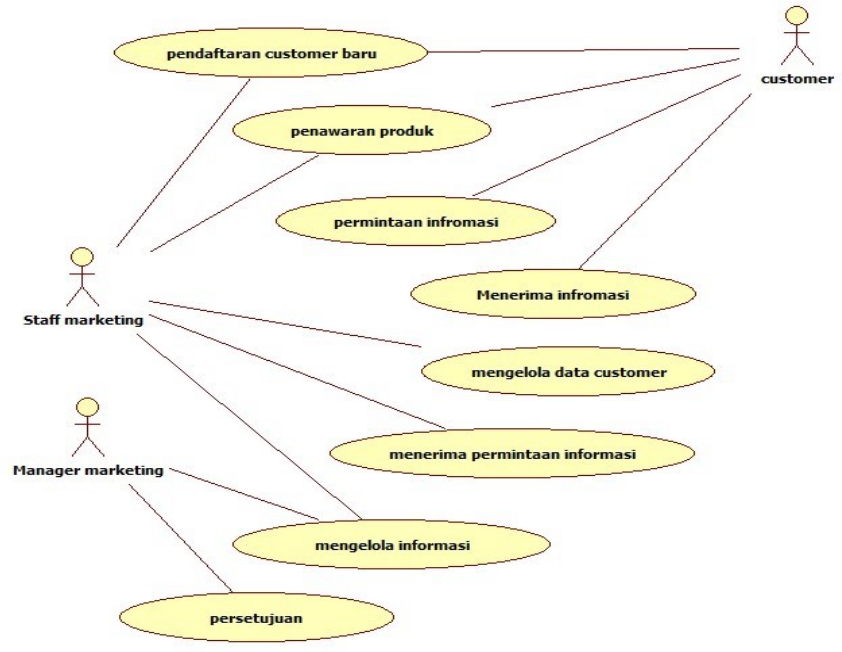

Gambar 5. Use Case Diagram Pemodelan Bisnis Sistem CRM

\section{Portfolio Management}

Disiplin portfolio management menggambarkan pemanfaatan IT/IS yang sedang berjalan.

1. Koleksi data IRC (Information Resue Catalog)

Data Integrated System (DIS) yang dimiliki saat ini adalah Sistem Informasi Enterprise Resource Planning yang di dalamnya terdapat empat modul utama yaitu: Marketing, Operasional, General Affair, dan Finance.

2. Temuan dan Observasi

Dari hasil temuan data IRC dapat digunakan sebagai alat analisis untuk menemukan beberapa kelemahan yang ada pada saat ini, selain itu juga dapat digunakan untuk memperoleh gambaran mengenai data-data yang dimanfaatkan oleh software dalam menunjang unit organisasi dalam perusahaan yang belum didukung oleh software.

Berdasarkan observasi yang dilakukan maka diperoleh fakta atau temuan terhadap pemanfaatan $\mathrm{TI}$ SI pada saat ini yaitu belum adanya sistem aplikasi yang mendukung proses bisnis terhadap managemen pelayanan customer.

\section{Architecture Enterprise}

Pada tahapan ini, ada beberapa aktivitas yang dilakukan yakni mendefinisikan kebutuhan arsitektur perusahaan meliputi: arsitektur aplikasi, data dan teknologi. Selanjutnya akan disesuaikan berdasarkan disiplin portfolio management yang telah dibahas pada tahapan sebelumnya.

1. Arsitektur Data

Arsitektur data bertujuan untuk mendefinisikan data yang akan dipakai dalam mengembangkan dan membangun arsitektur aplikasi. Arsitektur digambarkan menggunakan class diagram berdasarkan langkah yang ada pada disiplin arsitektur enteprise.

a. Entitas Data

Menentukan kandidat entitas didasarkan pada fungsi bisnis yang ada di organisasi berdasarkan value chain. Hasil dari pendefinisian tersebut menghasilkan kandidat entitas (list of entity) meliputi: Entitas Marketing, Entitas Perawatan Infrastruktur, dan Entitas proses pelayanan umum.

b. Relasi Entitas

Setelah pengidentifikasian entitas data pada proses utama yang mendukung dalam kegiatan operasional di perusahaan, maka selanjutnya akan dilakukan identifikasi dan pengelompokan data yang dibuat dan digunakan dalam proses tersebut. Dalam mendefinisikan arsitektur data, pada tahapan ini dibuat menggunakan class diagram, 
ILKOM Jurnal IImiah Volume 11 Nomor 3 Desember 2019

Terakreditasi peringkat 3 SK. No. 28/E/KPT/2019

dimaksudkan untuk menggambarkan relasi antar entitas data. Data yang sedang diidentifikasi harus dapat menentukan hal-hal sebagai berikut:

1) Akurasi, ketepatan waktu dan ketersediaan data yang diperlukan dalam mendukung kegiatan operasional di perusahaan.

2) Penyebaran data yang ada dan potensial diantara proses-proses yang saling berkaitan dalam hal ini berkaitan dengan integrasi data.

3) Data-data yang mendukung proses pada bisnis proses pelayanan pelanggan harus teridentifikasi dengan jelas.

Berdasarkan tiga kandidat entitas yang dihasilkan dari fungsi bisnis yang ada, maka dapat dibuat class diagram yang menggambarkan keterkaitan antar entitas data yang terlibat dalam fungsi tersebut sebagaimana ditunjukkan pada Gambar 6, Gambar 7, dan Gambar 8.

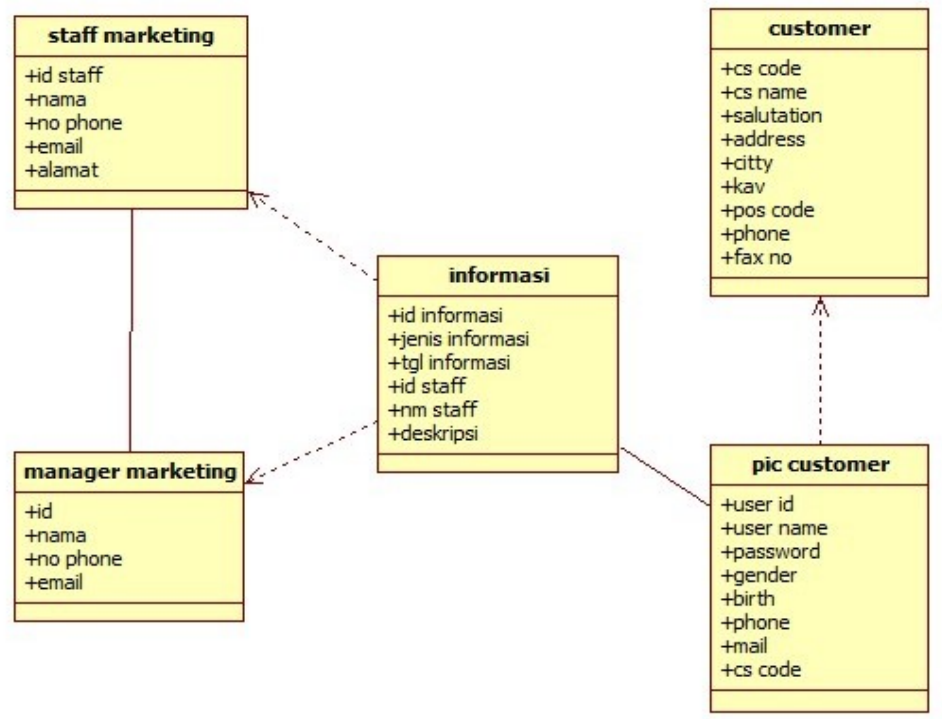

Gambar 6. Class Diagram Marketing

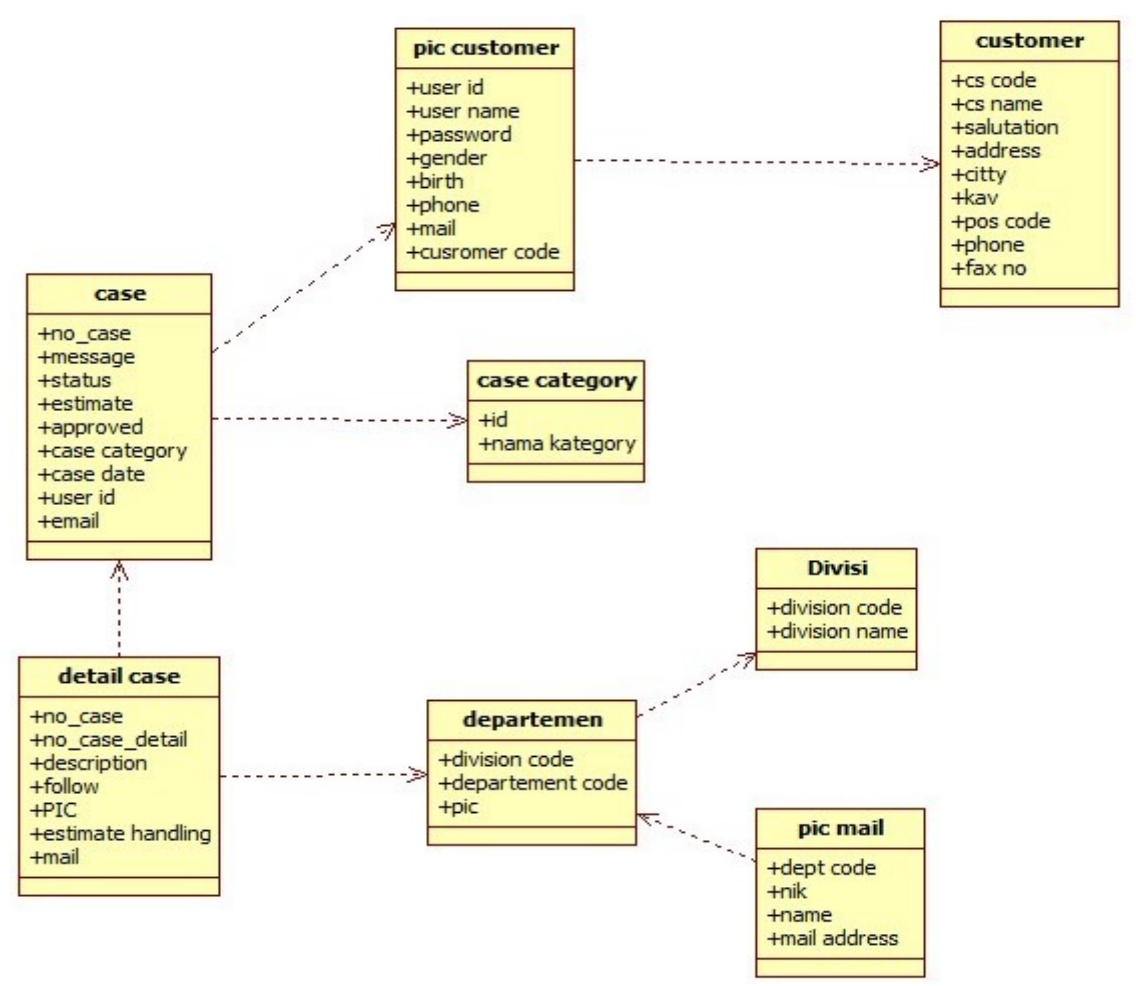

Gambar 7. Class Diagram Perawatan Infrastruktur 


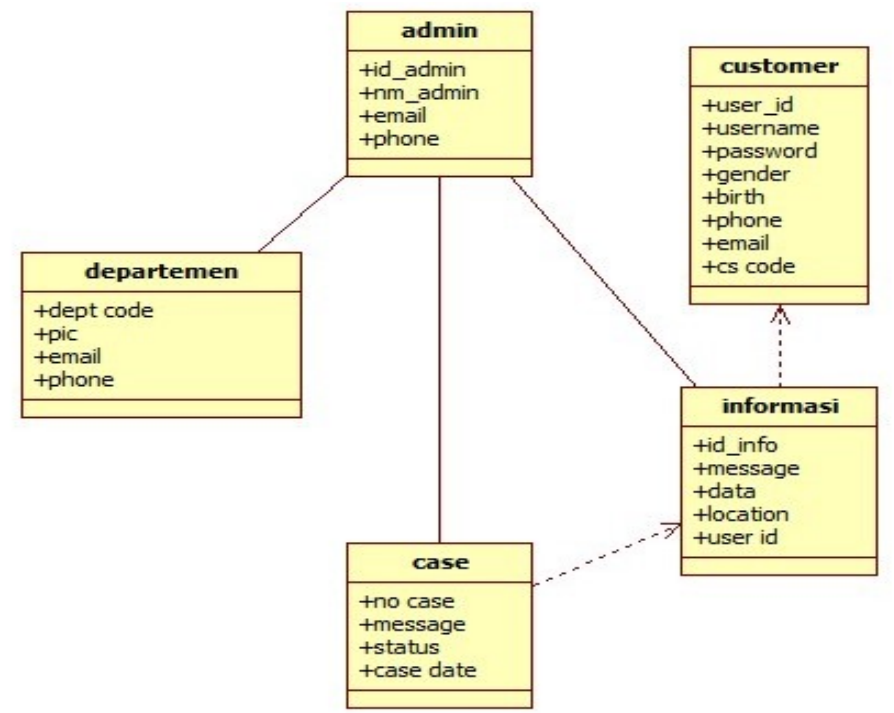

Gambar 8. Class Diagram Pelayanan umum

\section{Arsitektur Aplikasi}

Berdasarkan Use Case bisnis yang ada, maka dapat diidentifikasi kandidat aplikasi yang akan dibuat untuk mendukung aktivitas utama maupun aktivitas pendukung organisasi kedalam kelompokkelompok aplikasi sesuai dengan aktivitas yang ada menurut value chain.

a. Kelompok aplikasi marketing

1) Pendaftaran customer baru

2) Pengelolaan informasi

3) Penawaran produk

4) Pengelolaan data customer

b. Kelompok aplikasi perawatan infrastruktur

1) Pelaporan kasus infrastruktur

2) Pengelolaan data kasus infrastruktur

3) Informasi kasus infrastruktur

4) Penanganan kasus

c. Kelompok aplikasi pelayanan umum

1) Informasi kejadian

2) Pengelolaan data kejadian

3) Penanganan kejadian

\section{Strategic Reuse}

Setelah melakukan identifikasi arsitektur data dan arsitektur aplikasi, langkah selanjutnya yaitu mengusulkan pengembangan arsitektur teknologi guna membuat sistem. Pada disiplin strategic reuse, EUP akan menggambarkan aset teknologi yang sudah ada guna mengoptimalkan kinerja teknologi EUP di uraikan dengan mengggunakan:

1) Component diagram

2) Deployment diagram

3) Technology architecture

sebagaimana ditunjukkan pada Gambar 8, Gambar 9, dan Gambar 10 secara berturut-turut.

\section{People Management}

Dalam tahapan People Management, diuraikan mengenai manajemen sumberdaya manusia yang terlibat dalam pengembangan $\mathrm{SI} / \mathrm{TI}$ disesuaikan dengan usulan pada disiplin enterprise architecture mengenai arsitektur aplikasi, data dan teknologi yang dibutuhkan dalam perencanaan arsitektur enterprise. Hal ini bertujuan untuk untuk keberhasilan proyek-proyek dalam organisasi. Adapun tenaga ahli yang dibutuhkan seperti pada Tabel 1. 
ILKOM Jurnal Ilmiah Volume 11 Nomor 3 Desember 2019

Terakreditasi peringkat 3 SK. No. 28/E/KPT/2019

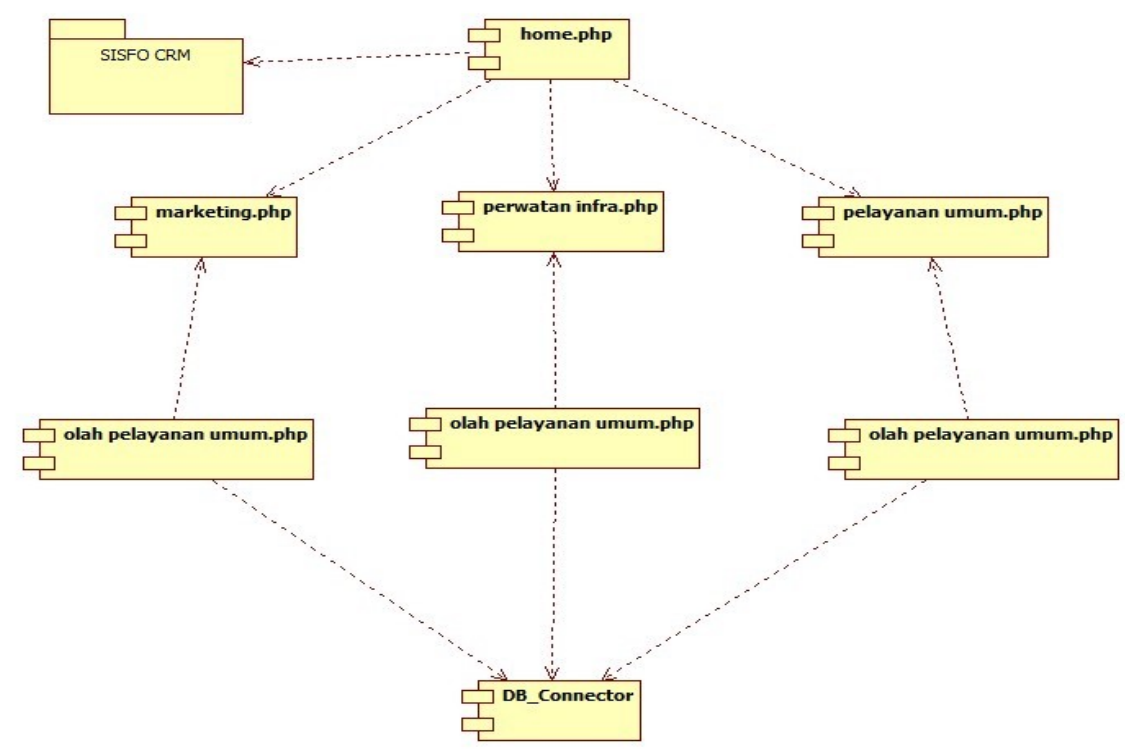

Gambar 8. Component diagram

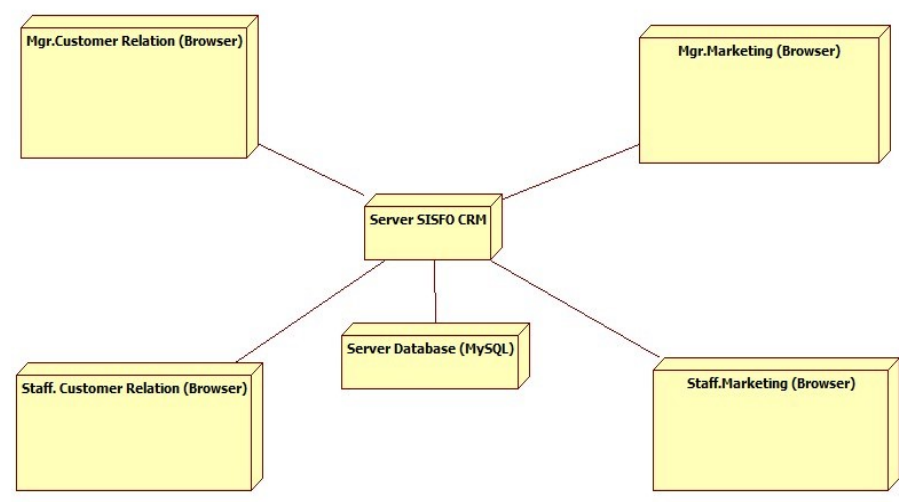

Gambar 9. Deployment Diagram

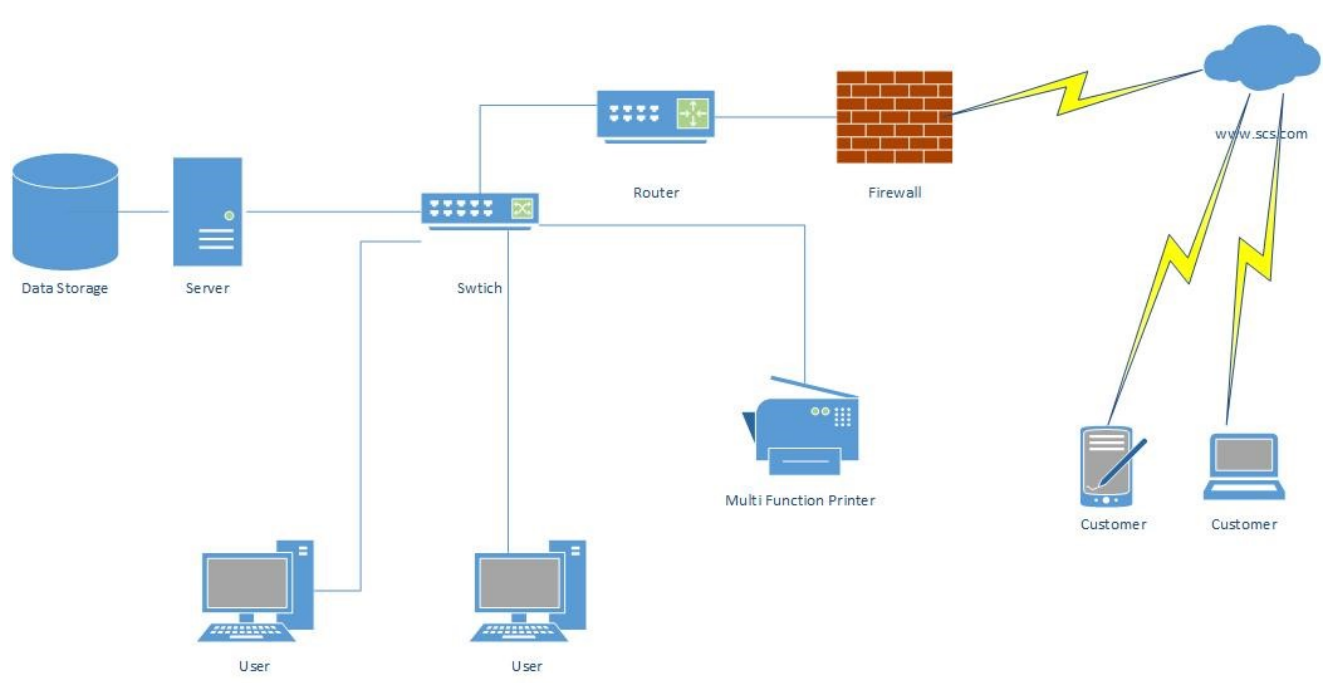

Gambar 10. Technology architecture 
ILKOM Jurnal Ilmiah Volume 11 Nomor 3 Desember 2019 Terakreditasi peringkat 3 SK. No. 28/E/KPT/2019

Tabel 1. Tenaga ahli

\begin{tabular}{clc}
\hline No & \multicolumn{1}{c}{ Posisi } & Jumlah Personel \\
\hline 1 & Enterprise Administrator & 1 \\
2 & System Analys & 2 \\
3 & Programmer & 2 \\
4 & Database Administrator & 2 \\
5 & Network Administrator & 1 \\
\hline
\end{tabular}

Adapun tanggung jawab dari masing-masing posisi-posisi akan dijelaskan sebagai berikut:

1. Enterprise Administrator bertanggung jawab penuh terhadap arsitektur enterprise dan menterjemahkan arsitektur enterprise meliputi arsitektur aplikasi, data dan teknologi

2. System Analysis bertanggung jawab mempelajari masalah dan kebutuhan sebuah organisasi untuk dapat mendefinisikan bagaimana metode dan teknologi yang dapat mendukung bisnis dengan baik, serta membuat desain yang dibutuhkan.

3. Programmer bertanggung jawab menerjemahkan desain ke dalam bentuk source code pemrograman.

4. Database Administrator bertanggung jawab merancang dan mengelola database yang akan digunakan dalam pengembangan sistem

5. Network Administrator bertanggung jawab merancang skema jaringan komputer dan mempersiapkan kebutuhan jaringan yang diperlukan dalam pengembangan sistem.

\section{Enterprise Administration}

Pada disiplin ini akan dideskripsikan bagaimana pengelolaan dan pemeliharaan asset $\mathrm{TI} / \mathrm{SI}$ yang ada pada perusahaan. Dalam hal ini ada beberapa tahapan pada Enterprise Administration diantaranya yaitu :

1. Mengelola asset fisik

2. Mengelola Pengamana Asset Informasi

3. Mengelola lisensi Software

\section{Software Process Improvement}

Dalam disiplin ini berkaitan dengan usulan penggunaan metode pengembangan perangkat lunak. Penulis menyarankan untuk menggunakan metode pengembangan sistem dengan menggunakan Rational Unified Process (RUP). Pada dasarnya RUP ini untuk memastikan produksi perangkat lunak yang berkualitas tinggi yang memenuhi kebutuhan end-user, dengan jadwal dan anggaran yang terprediksi EUP dan RUP ini saling melengkapi satu sama lain. EUP mengenai siklus arsitektur enterprise dan RUP mengenai siklus perancangan sistem yang memungkin setiap sistemnya dikembangkan dengan berorientasi objek.

\section{Kesimpulan dan Saran}

Berdasarkan dari hasil penelitian yang dijelaskan pada hasil dan pembahasan yang berpedoman pada tahap-tahap penelitian maka dapat disimpulkan bahwa (1) Dihasilkan rekomendasi sistem yang strategis dan berpotensi untuk dibangun guna mendukung proses bisnis dalam organisasi. (2) Model arsitektur enterprise yang dihasilkan dapat sebagai acuan untuk mencapai sasaran strategis organisasi. Selain itu, dapat sebagai pedoman dalam menentukan kebijakan pengembangan $\mathrm{TI} / \mathrm{SI}$ sehingga terukur dengan jelas. (3) Memperolah usulan arsitektur enterprise dengan metode Enterprise Unified Process (EUP) yang mendukung proses bisnis dan metode pengembangan sistem menggunakan metode Rational Unified Process (RUP).

Berdasarkan hasil penelitian ini, beberapa saran yang dapat diajukan adalah sebagai berikut (1) Cakupan pembahasan sistem Customer Relationship Managament agar diperluas dengan mengutamakan pada customer focus. (2) Melakukan penelitian lebih dalam mengenai bisnis proses Customer Relationship Management. (3) Setiap unit organisasi harus dipastikan mendapatkan sosialisasi pembangunan atau pengembangan Sistem Informasi. Ini diperlukan agar setiap unit dapat memberikan kontribusi yang sangat bermanfaat bagi pengembangan selanjutnya. 


\section{Daftar Pustaka}

[1] Mulyanto, A., Pengertian Sistem Informasi dalam Sistem Informasi Konsep dan Aplikasi. Yogyakarta: ANDI, 2009.

[2] Dyantina, O., Afrina. M., Ibrahim, A., "Penerapan Customer Relationship Management (CRM) Berbasis Web (Studi Kasus Pada Sistem Informasi Pemasaran di Toko YEN-YEN)", Jurnal Sistem Informasi, Vol.4 .No.2, 2012.

[3] Nurfadillah, Y., dan Setiawan, R., "Pengembangan Aplikasi Pengendalian Tugas Akhir Berbasis Web Sisi Mahasiswa, Dosen, Dan Staff USI”, Jurnal STT-Garut, Vol. 13. No. 01, 2016.

[4] Victor, C.,Jorie,J.R., dan Sumarauw,J.S.B., "Pengaruh Customer Relationship Management Dan Kepercayaan Terhadap Kepuasan Serta Dampaknya Terhadap Loyalitas Konsumen PT. Bank Bca Tbk. Di Manado", Jurnal EMBA, Vol. 3, No.2, 2015.

[5] Pereira, C. M. dan SOUSA, P., "A Method to Define an Enterprise Architecture Using the Zachman Framework", Proceeding at the ACM Symposium on Applied Computing, 2004.

[6] Abdurrahman, J., Hamdani, D., dan Novantara, P., "Implementasi Customer Relationship Management (CRM) Pada Penerimaan Siswa Baru (Studi Kasus di Pondok Pesantren Darussalam Kabupaten Garut)", Jurnal Nuansa Informatika, Vol. 12, No. 1, 2018.

[7] Gaffar, Vanessa., 2007. CRM dan MPR Hotel, Bandung: Alfabeta.

[8] Victor, C.,Jorie, J.R., dan Sumarauw, J.S.B., "Pengaruh Customer Relationship Management Dan Kepercayaan Terhadap Kepuasan Serta Dampaknya Terhadap Loyalitas Konsumen PT. Bank Bca Tbk. Di Manado", Jurnal EMBA Vol. 3, No.2, 2015.

[9] Ambler. S.W., 2005. The Enterprise Unified Process: Extending the Rational Unified Process.

[10] IBM., Business Systems Planning: Information System Planning Guide, New York, USA: International Business Machines Corporation, 1987.

[11] Hadiana, A., Perencanaan dan Pengembangan Sistem Infromasi Terpadu. Megatama, Bandung, 2016.

[12] Pereira, C. M. dan SOUSA, P., "A Method to Define an Enterprise Architecture Using the Zachman Framework", Proceeding at the ACM Symposium on Applied Computing, 2004.

[13] Buttle, F., Customer Relationship Management (Manajemen Hubungan Pelanggan), Terjemahan oleh Arief Subiyanto, Malang : Bayu Media Publishing, 2007.

[14] Porter, M, E., Competitive Advantage: Creating and Sustaining Superior Performance for Analyzing Industries and Competitor, 1985.

[15] Irmayani, W., "Perancangan Strategis Sistem dan Teknologi Informasi pada Dinas Cipta Karya, Tata Ruang, dan Kebersihan Kabupaten Kubu Raya, Kalimantan Barat". Jurnal Informatika dan Sisptem Informasi 2(1), 16-25, 2016. 